\title{
Distrofias hereditárias da retina e principais avanços no estudo da atrofia progressiva de retina - Um modelo para a retinose pigmentar dos seres humanos
}

\author{
Hereditary retinal dystrophies and advances in the study of progressive \\ retinal atrophy - $A$ model for human retinitis pigmentosa
}

Henrique de Moura Freitas (D)*, Fabiano Montiani-Ferreira (D)

Programa de Pós-Graduação em Ciências Veterinárias, Universidade Federal do Paraná (UFPR), Curitiba, PR, Brasil

\section{Resumo}

As distrofias de retina são causas comuns de cegueira em seres humanos, em cães e em outros animais. Dentre as principais distrofias diagnosticadas em seres humanos estão a amaurose congênita de Leber e a retinose pigmentar. Essas duas doenças possuem semelhança com distrofias hereditárias encontradas em cães, sendo a retinose pigmentar muito semelhante à atrofia progressiva de retina. 0 objetivo do presente trabalho é descrever esse complexo de doenças por meio de uma revisão de literatura. 0 estudo dos modelos experimentais em animais possibilita a identificação de genes responsáveis por essas doenças e permitem a elucidação de novos tratamentos, como a terapia gênica e testes genéticos. Assim, o estudo das distrofias hereditárias em animais é essencial para o entendimento dessas doenças em seres humanos.

Palavras-chave: Distrofias de retina. Atrofia progressiva de retina. Modelos experimentais em animais.

\section{Abstract}

Retinal dystrophies are common causes of blindness in humans, dogs, and other animals. Among the main dystrophies diagnosed in humans are the Leber's congenital amaurosis and retinitis pigmentosa. These two diseases resemble hereditary dystrophies found in dogs, as evidenced by retinitis pigmentosa and its similarity to progressive retinal atrophy. The goal of this work is to describe this group of diseases through a literature review. Experimental models in animals allow for the identification of the genes responsible for these diseases, in addition to fostering new treatments, such as gene therapy, and more concrete diagnostic methods such as genetic tests. Thus, the study of hereditary dystrophies in animals is essential for understanding these diseases in humans.

Keywords: Retinal dystrophies. Progressive retinal atrophy. Animal models. 


\section{Introdução}

A visão é uma importante adaptação evolutiva dos animais que proporciona condições para ocuparem os mais diversos nichos, seja em locais com baixa intensidade de luz ou bem iluminados, dependendo da característica de suas células fotorreceptoras. Essas células fazem parte de uma estrutura nervosa chamada retina, que transforma estímulos luminosos em impulsos nervosos em um processo chamado fototransdução (Ofri, 2013). Entre as principais afecções da retina estão as distrofias hereditárias.

As distrofias hereditárias da retina causam perda progressiva da visão e são a principal causa de cegueira herdada em seres humanos, fato decorrente da morte progressiva de fotorreceptores. Uma em cada 4000 pessoas é afetada por esse grupo de doenças e cerca de 4,5 milhões de pessoas em todo o mundo foram documentadas com algum tipo de distrofia hereditária até o ano de 2016 (Hartong et al., 2006; Hohman, 2016). Esse grupo heterogêneo de doenças é caracterizado pela degeneração dos cones e bastonetes encontrados na camada de fotorreceptores da neurorretina, camada responsável pelo fenômeno de fototransdução. $\mathrm{Na}$ medicina, as principais distrofias retinianas caracterizadas nesse grupo são a retinose pigmentar (RP), a amaurose congênita de Leber (ACL), a doença de Stargardt, a distrofia macular de Best e a síndrome de Usher (Bernardis et al., 2016).

Com o avanço da tecnologia foi possível elucidar a origem dessas doenças. Por meio de modelos experimentais e análises biomoleculares, vários genes defeituosos envolvidos na patogenicidade dessas distrofias foram revelados. Distrofias retinianas ocorrem espontaneamente nos animais, que, assim, podem servir como modelos experimentais, contribuindo para o melhor entendimento da patofisiologia dessas doenças. As mutações na subunidade beta da enzima GMP cíclico fosfodiesterase, por exemplo, causam distrofias retinianas em camundongos, em cães da raça Setter Irlandês e em seres humanos. Desta forma, animais com distrofias homólogas a dos seres humanos podem ser utilizados como modelos de investigação de novos tratamentos com o uso de drogas ou terapia gênica (Petersen-Jones, 1998a).

\section{Desenvolvimento}

\section{0 uso de cães como modelo experimental para doenças da retina}

São conhecidas pelo menos 400 raças de cães. Tais raças possuem fenótipos variados, seja na constituição corporal, comportamento ou até mesmo na expressão de determinados genes. Pelo menos 450 doenças hereditárias que acometem os cães já foram reconhecidas e descritas (Switonski, 2013).

Essa variabilidade genética também reflete na patofisiologia ocular, proporcionando semelhanças quanto às doenças que acometem seres humanos e animais. A RP, distrofia de retina mais estudada por meio de modelos animais, trata-se de uma condição que progressivamente causa déficit visual periférico e nictalopia (cegueira noturna) em seres humanos. São conhecidos pelo menos 40 genes que podem causar RP. Essa condição pode ser herdada de maneira autossômica recessiva, autossômica dominante ou ainda pode ser ligada ao cromossomo $\mathrm{X}$. O uso de animais como modelos para o seu entendimento é de suma importância para elucidar os genes responsáveis, características clínicas e até mesmo os mecanismos celulares que causam a manifestação dessa doença em seres humanos, possibilitando, assim, o desenvolvimento de tratamentos. A atrofia progressiva de retina (APR) é uma doença análoga à RP, que acomete mais de 100 raças de cães. Foram descritos pelo menos 12 genes envolvidos nessa doença e esses representam semelhanças genotípicas e fenotípicas com os genes da RP (Beltran et al., 2009).

\section{Terapia gênica}

A terapia gênica tem o intuito de alterar os mecanismos genéticos responsáveis por doenças como câncer, imunodeficiências hereditárias, talassemias, hemofilia e doenças da retina (Naldini, 2015).

Um dos genes mais estudados nas distrofias de retina é o RPE65, responsável pela tradução de uma proteína abundante no epitélio pigmentar da retina (EPR), que é responsável direta pelo metabolismo da vitamina A. Sabe-se, no entanto, que mutações nesse gene levam a distrofias de retina em animais e seres humanos. Le Meur et al. (2007) demostraram 
que a terapia gênica, pela injeção subretiniana de adenovírus recombinante do tipo 2 (AAV2) na região tapetal da retina de cães da raça Briard, possibilitou a recuperação visual e funcional da retina em todos os cães que passaram por esse procedimento no prazo de 12 meses após uma única aplicação do vetor. Sabe-se que até aquele momento não existia nenhum tratamento eficiente para essas distrofias tanto em cães quanto em seres humanos. Vários ensaios clínicos em seres humanos já foram realizados desde então, sendo que em um deles, realizado em cinco pacientes, houve significativa melhora clínica do quadro de ACL, com a visão dos pacientes preservada durante 36 meses de avaliação após o tratamento (Naldini, 2015).

\section{Atrofia progressiva de retina}

As distrofias retinianas são comuns em cães de raça pura. Dentre as principais distrofias estão as APRs, já caracterizadas em mais de 100 raças diferentes (Miyadera et al., 2012). As APRs estão no grupo de distrofias retinianas hereditárias e causam perda progressiva da visão, levando à cegueira.

\section{Fisiopatologia}

No início da doença são afetados mais comumente os bastonetes, que são células fotorreceptoras responsáveis pela captação de estímulos luminosos de baixa intensidade de luz e pela percepção do movimento, causando nictalopia (déficit visual noturno). Com a evolução desse processo também são acometidos os cones, que são fotorreceptores retinianos responsáveis pela captação de estímulos luminosos de maior intensidade e pela percepção das cores, afetando, assim, a visão diurna (PetersenJones, 2005). Todavia, existem distrofias de retina que se iniciam com degeneração dos cones antes dos bastonetes, como as cone-rod dystrophies (crd) (Mellersh et al., 2006).

Associados a esses eventos, a APR tem por sinais clínicos mudanças no aspecto do fundo de olho visíveis à oftalmoscopia, como hiperrefletividade do fundo tapetal, atenuação dos vasos da retina e atrofia do disco óptico, na maioria das vezes acompanhada por catarata secundária bilateral (Miyadera et al., 2012) (Figura 1).
A retina na APR torna-se cada vez mais fina, facilitando a refletividade da luz, de maneira a incrementar a refletividade tapetal. A periferia da retina torna-se de aspecto granular e, com o avanço da doença, o sangue deixa de passar pelos vasos retinianos, evidenciado a fundoscopia pela atenuação dos vasos e por aglomerados de pigmentos na região tapetal. Tal característica é consequência da intensa atividade fagocítica do epitélio pigmentar retiniano, que deixa ali os resquícios dos fotorreceptores na forma de grânulos de lipofuscina (Kennedy et al., 1995). Concomitantemente, ocorrem áreas de despigmentação do fundo não tapetal, um fenômeno denominado de "pavimentação," e os axônios das células ganglionares começam a se degenerar, tornando o aspecto da papila óptica mais acinzentado devido à perda da mielina (Petersen-Jones, 2005).

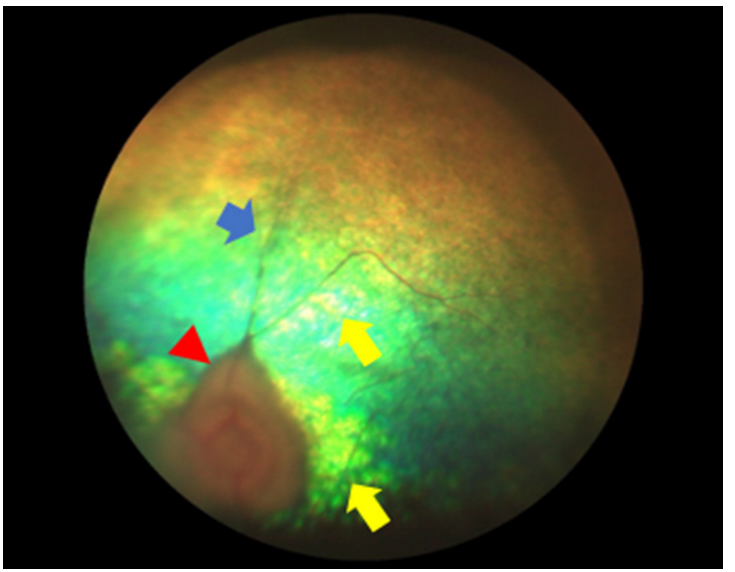

Figura 1 - Fundo de olho de cadela da raça Labrador Retriever de 8 anos, em estágio final de atrofia progressiva de retina. Notam-se áreas de hiperrefletividade (setas amarelas) na região tapetal e ao redor do disco óptico, diminuição do calibre das arteríolas e vênulas (seta azul) e palidez do disco óptico (ponta de seta vermelha). Nota-se, também, que os vasos sobre o disco óptico estão bastante diminuídos de calibre.

\section{Classificação}

A APR pode ser classificada pela idade de início dos sinais clínicos e pela taxa de progressão. Desta forma, algumas formas são de início precoce e outras de início tardio, sendo estas tipicamente de progressão mais lenta (Petersen-Jones, 2005). 
AAPR de desenvolvimento precoce normalmente se desenvolve durante o período pós-natal de maturação da retina (2 - 6 semanas de vida), resultando do desenvolvimento retiniano anormal ou degeneração progressiva, que se inicia durante ou imediatamente após a retinogênese. Normalmente tem progressão rápida e alcança seus estágios finais um pouco antes de o cão se tornar adulto. Em contrapartida, a APR de início tardio ocorre após o desenvolvimento da retina e tem por características a baixa viabilidade dos fotorreceptores e o comprometimento das suas funções, no entanto os sinais clínicos podem aparecer somente no final da vida do animal (Miyadera et al., 2012).

\section{Diagnóstico e epidemiologia}

A análise eletrorretinográfica (ERG) é de grande importância para o diagnóstico definitivo das APRs. Esse método de diagnóstico foi utilizado pela primeira vez por Dewar, em 1877, mas não foi publicado (Dantas, 1995). Gotch, em 1876, foi o primeiro a separar o resultado da ERG em duas ondas (Bacellar et al., 2008). Einthoven e Jolly (1908) foram os primeiros a observar em detalhes um traçado eletrorretinográfico do olho de um sapo a partir de um galvanômetro. Perry, Thomson e Tansley, em 1953, foram os precursores dos estudos eletrorretinográficos em cães (Balicka et al., 2016).

Esse método se baseia na estimulação dos fotorreceptores da retina por meio de flashes de luz, e na transferência desse estímulo elétrico para um aparelho eletrônico que amplifica o sinal elétrico e registra a atividade retiniana em ondas eletrorretinográficas. Essas podem estar ausentes quando o processo de fototransdução não ocorre efetivamente, sugerindo falha de transmissão de fora para dentro da retina (Acland e Aguirre, 1987; Gearhart et al., 2008). Esse exame é essencial na avaliação pré-cirúrgica da catarata (Komáromy et al., 1998), pois sabe-se que cães com APR muitas vezes apresentam catarata bilateral. Nesses casos, a cirurgia de catarata não faz com que o animal volte a enxergar, tendo caráter somente preventivo a fim de reduzir os efeitos da inflamação causada pela catarata, ou exclusivamente estético. É importante frisar que a ERG normal não garante que o animal esteja enxergando, mas sim que a fototransdução está acontecendo. Nos casos de degenerações da retina, a ERG pode registrar alterações elétricas antes mesmo de serem visibilizadas por meio da oftalmoscopia alterações do fundo de olho (Ekesten, 2013).

Existem diversos tipos de ERG, como o flash ERG (FERG), long flash ERG, scotopic threshold response (STR) e o photopic negative response (PhNR). 0 FERG é o mais utilizado para a avaliação da retina de cães no pré-cirúrgico de catarata e geralmente avalia a retina como um todo, não diferenciando a resposta elétrica dos diferentes fotorreceptores, a não ser que seja feita adaptação ao escuro ou ao claro ou que seja utilizado um foco de luz cromática (Ekesten, 2013).

Todavia, na suspeita de APR, a ERG ajuda a diferenciar os possíveis diagnósticos de SARDs (sudden acquired retinal degeneration syndrome), neurite ótica e cegueira central (Komáromy et al., 2016), que causam sinais clínicos semelhantes aos da APR.

\section{Os testes de DNA}

As distrofias da retina têm caráter hereditário e foram identificados pelo menos 172 genes associados à doença em seres humanos e diversas raças de cães, sendo na maioria autossômicos recessivos (Petersen-Jones, 2005; Miyadera et al., 2012). A literatura descreve como as raças mais acometidas pela APR o Poodle Toy, o Labrador Retriever e o Cocker Spaniel Inglês (Petersen-Jones, 1998b).

Por se tratar de uma alteração hereditária, a investigação biomolecular é muito importante nessa doença, uma vez que há grande possibilidade de ser transmitida para a geração seguinte. Desta forma, é desejável conhecer o perfil genético dos doentes, uma vez que já existem vários testes moleculares validados no mercado que possibilitam a identificação de diversos genes mutantes (Petersen-Jones, 2005).

A era dos testes de DNA se iniciou no Reino Unido, onde Clements et al. (1993) criaram um teste para identificação do gene rcd1 (rod-cone dysplasia 1), que causa displasia de bastões e cones em cães da raça Setter Irlandês e que tinha sido identificado no mesmo ano por Suber et al. (1993). A principal intenção da criação desses testes era evitar que cães que expressassem esses genes mutantes passassem essa característica para sua progênie, combatendo 
o fenótipo da doença dentro da raça estudada. Assim, os testes de DNA permitiam a identificação de animais afetados antes mesmo da expressão dos sinais clínicos da doença (Petersen-Jones, 2001).

A maioria dos testes de DNA, disponibilizados por empresas como a OptiGen ${ }^{\circledR}$, tem como objetivo identificar possíveis mutações nos genes de interesse. Trata-se de um processo custoso e bastante demorado, facilitado com o mapeamento do genoma canino. Pelo menos sete diferentes testes foram descritos até o início do presente século, entretanto eles só identificam a mutação de interesse, ou seja, se o animal tiver outro gene que também cause APR, esta não será diagnosticada (Petersen-Jones, 2001).

Outra forma de investigação diagnóstica possível são os testes baseados em linkage, os quais utilizam marcadores de DNA que se posicionam próximo do gene de interesse. 0 principal teste baseado em linkage é um marcador do gene progressive rodcone degeneration (prcd), que está relacionado ao desenvolvimento de APR em cerca de 29 raças de cães. A principal limitação desses testes é que sempre existe a possibilidade de ocorrer crossover entre o gene da doença e o marcador durante a meiose (Petersen-Jones, 2001).

Além do estudo eletrorretinográfico e dos testes biomoleculares, a avaliação histopatológica é de suma importância para o diagnóstico de APR. Ela permite a identificação do tipo celular afetado e verifica, por meio de técnicas de imunohistoquímica, se primeiramente ocorreu a degeneração ou se simplesmente o desenvolvimento celular foi incompleto (Petersen-Jones, 2005). Outro método de diagnóstico é a tomografia de coerência óptica (OCT), que possibilita a visualização de imagens da retina semelhantes a cortes histológicos in vivo (Huang et al., 1991, 1998; Hamada et al., 2000; Somma et al., 2017).

\section{Principais tipos de APR}

Diversos tipos de APR já foram descritos e muitos genes já foram relacionados à doença (Tabela1). Entre as APRs, destaca-se a prcd, análoga à RP e objeto importante de estudo como modelo da doença encontrada em seres humanos. Nessa doença ocorre degeneração tanto de cones quanto de bastonetes nos aspectos estruturais e funcionais de maneira tardia, ou seja, a doença não se manifesta até o animal se tornar jovem ou adulto. Acland et al. (1998) sugerem que o loci responsável pela prcd está no cromossomo canino número nove. Poodle, Cocker Spaniel e Labrador Retriever são as raças mais acometidas por esse tipo de APR, e a mesma mutação pode causar sinais clínicos diferentes em diferentes raças (Petersen-Jones, 1998b).

No caso dos Poodles, a nictalopia se manifesta tipicamente entre 3 e 5 anos de idade, normalmente acompanhada de sinais de degeneração precoce e formação de catarata secundária. As alterações no ERG podem não ocorrer até 28 semanas de idade (Aguirre et al., 1982). No Cocker Spaniel, a doença se comporta de maneira mais tardia e com progressão mais lenta do que no Poodle, sendo que as alterações no ERG não costumam ocorrer até 2 anos de idade. Nessa raça, a degeneração retiniana costuma poupar o canto nasal e temporal, formando "ilhas" (PetersenJones, 1998b). Mais recentemente, Svensson et al. (2016) relataram um tipo de APR (prcd) em cães da raça Pastor Polonês da Planície que foi definida como distrofia de início tardio. 0 primeiro sinal da doença foi uma atenuação vascular discreta, mas facilmente visível na periferia do fundo ocular, sem indicativo de hiperrefletividade tapetal. Os donos dos animais relataram que os mesmos tinham medo de escuro, mas sem sinais de nictalopia. Uma redução na função dos bastonetes foi detectada por meio do ERG, estando inclusive a amplitude das ondas reduzida mesmo sem sinais de degeneração na oftalmoscopia. Nesse estudo, a doença demonstrou progressão bastante lenta, de maneira que alguns animais ainda enxergavam mesmo com 10-11 anos de idade.

A rod/cone dysplasia (rcd) é um tipo de APR de início precoce. Em cães afetados, a retina permanece normal até por volta de 13 dias de idade (Suber et al., 1993) e vai sofrendo progressiva degeneração, primeiro de fotorreceptores e depois de todas as camadas da retina (Petersen-Jones, 2005). Existem três formas de rcd conhecidas: rcd1, descrita pela primeira vez na raça Setter Irlandês (Aguirre et al., 1978); rcd2, descrita pela primeira vez na raça Collie (Wolf et al., 1978); e rcd3, descrita no Welsh Corgi Cardigan (Petersen-Jones et al., 1999). A rcd1 foi a primeira APR em que o gene de mutação foi 
identificado. Estudos demonstraram que os filhotes afetados possuíam acúmulo anormal de GMPc em suas retinas; cães com essa alteração normalmente ficam cegos antes de 1 ano de idade (DjajadiningratLaanen et al., 2003). Em rcd2 também foi descrita a falha na hidrólise de GMP e posterior acúmulo na retina, mas essa concentração diminui rapidamente, uma vez que os fotorreceptores já sofreram degeneração (Acland et al., 1989). A rcd3 foi descrita como muito similar ao rcd1, mas em vez de ocorrer mutação na subunidade $\beta$ da GMPc fosfodiesterase, ocorre na subunidade $\alpha$, e não há muitas descrições a respeito da clínica da doença (Petersen-Jones et al., 1999).

Existem três APRs que são descritas como ligadas ao cromossomo X (XLPRA): a XLPRA1 ocorre no Husky Siberiano (Acland et al., 1994) e no Samoieda; a XLPRA2 foi identificada em uma linha de cães sem raça definida (Petersen-Jones, 2005); e a XLPRA3 foi identificada em Border Collies (Vilboux et al., 2008). Na XLPR1 ocorre a morte dos bastonetes antes dos cones e os sinais no ERG aparecem logo aos 6 meses de idade. 0 estágio final da doença, com substancial hiperrefletividade tapetal e acentuada atenuação dos vasos retinianos, ocorre por volta dos 4 anos de idade. Alteração nas ondas do ERG também ocorre por volta dos 6 meses na XLPRA2, mas os sinais de degeneração da retina e a total perda de função ocorrem por volta dos 2 anos de idade (Petersen-Jones, 2005). Kropatsch et al. (2016) também relataram esse tipo de APR em cães da raça Weimaraner. A XLPRA3, descrita por pesquisadores franceses, tem por característica a nictalopia e perda da visão diurna de maneira progressiva, evoluindo para cegueira total entre 3 e 4 anos de idade; nas alterações nas ondas da ERG foram observadas a partir de 2 anos de idade (Vilboux et al., 2008).

Kijas et al. (2003) descreveram uma forma de APR com herança dominante no Mastiff Inglês e no Bull Mastiff. Os cães afetados tinham alterações no ERG por volta dos 12-18 meses de idade. Nessa afecção, a retina central era afetada antes da periferia e a hiperreflexia normalmente era ao redor e na lateral da papila óptica. Nesta APR não se conhece com exatidão a sua patogenia, mas sabe-se que ocorre a mutação do gene que codifica a porção proteica da rodopsina (Petersen-Jones, 2005).
Acland e Aguirre (1987) descreveram uma early retinal degeneration (erd), uma distrofia precoce, mas de progressão lenta, em que a disgenesia dos fotorreceptores é seguida de degeneração estrutural e perda de função da retina. Essa afecção foi descrita na raça Elkhound Norueguês, acompanhada de nictalopia após 6 semanas de idade e cegueira com 12-18 meses de idade. Com cerca de 1 ano de idade, a ERG desses cães demonstrou ausência de ondas (Petersen-Jones, 1998).

Aguirre e Rubin (1971) descreveram um tipo de rod dysplasia (rd) em Elkhound Norueguês que tinha como sinais clínicos nictalopia após os 6 meses de idade e cegueira total entre 3 e 5 anos, sendo que não havia hiperrefletividade tapetal até 2 anos de idade. Devido à degeneração da retina, o ERG não é normal nessa APR (Petersen-Jones, 1998b).

Parshall et al. (1991) reportaram uma APR em que foi descrito um tipo de photoreceptor dysplasia (pd) em Schnauzer miniatura. Essa afecção é caracterizada por ser de início precoce. O histopatológico e a ERG demonstraram danos à retina logo nos primeiros dias de vida do animal, mas os sinais de degeneração observados por meio da fundoscopia são muito tardios. Os bastonetes são afetados mais rapidamente do que os cones, fato é que após os 6 meses de idade os cones se tornaram predominantes na camada de fotorreceptores da retina desses animais.

Curtis e Barnett (1993) reportaram um tipo de APR generalizada em Dachshund miniatura de pelo longo. Os cães afetados apresentaram sinais de degeneração retiniana por meio da oftalmoscopia logo aos 6 meses, idade na qual se iniciou a nictalopia. Os autores relataram marcada variação na progressão da doença nesses cães, necessitando de mais estudos. O ERG apresentava alterações a partir dos 9 meses de idade, e os autores sugeriram a utilização dessa doença como modelo para a RP.

Barnett e Curtis (1978) descreveram um tipo diferente de APR no Terrier Tibetano. Essa distrofia tinha por principais características nictalopia e sinais de degeneração da retina na oftalmoscopia a partir de 1 ano de idade, com alterações no ERG a partir dos 10 meses de idade. A perda de fotorreceptores também se iniciava nos bastões, até progredir para os cones e culminar na atrofia da retina por completo. 
Tabela 1 - Raças de cães descritas com distrofias de retina, nomes das condições clínicas e respectivos genes associados à doença

\begin{tabular}{|c|c|c|}
\hline Tipos de atrofia progressiva de retina (APR) & Gene & Raças conhecidas \\
\hline Acromatopsia (ACHM) & CNGB3 & Ponter Inglês de pelo curto \\
\hline Amaurose congênita de Leber canina & cLCA & Briard \\
\hline APR autossômica dominante (aDPRA) & $\mathrm{RHO}$ & Bullmastiff e Mastiff Inglês \\
\hline APR do Golden Retriever Tipo 1 (GRPRA1) & SLC4A3 & Golden Retriever \\
\hline APR do Golden Retriever Tipo 2 (GRPRA2) & TTC8 & Golden Retriever, Labrador Retriever \\
\hline APR generalizada (gPRA) & CCDC66 & Schapendoes \\
\hline APR Tipo A & PCD & Schnauzer miniatura \\
\hline Atrofia progressiva de retina do Tipo 3 (PRA3) & FAN161A & Spaniel Tibetano e Terrier Tibetano \\
\hline Degeneração de cones e bastonetes do Tipo 4 (RCD4) & C20RF71 & Setter de Gordon, Setter Irlandês, Setter Inglês e Terrier Tibetano \\
\hline Degeneração retiniana precoce (ERD) & STK38L & Elkhound Norueguês \\
\hline Distrofia de cone-bastão (CRD) & NPHP4 & Dachshund (wire-haired) standard \\
\hline Distrofia de cone-bastão 1 (CORD1) & RPGRIP1 & Dachshund miniatura de pelo longo \\
\hline Displasia de bastão-cone (RCD1) & PDE6B & Setter Irlandês e Sloughi \\
\hline Distrofia de cone e bastão do Tipo 3 (CRD3) & ADAM9 & Terrier do Glenn do Imaal \\
\hline Distrofia de bastão e cone do Tipo 3 (RCD3) & PDE6A & Welsh Corgi Cardigan \\
\hline Degeneração progressiva de bastão-cone (PRCD) & PRCD & $\begin{array}{l}\text { Cocker Spaniel Americano, Cão Esquimó Americano, Australian } \\
\text { Cattle Dog, Pastor Australiano, Pastor Australiano (miniatura), } \\
\text { Australian Stumpy Tail Cattle Dog, Cheseapeake Bay Retriever, Cão } \\
\text { de Crista Chinês, Poodle, Markiesje, Cocker Spaniel Inglês, Boiadeiro } \\
\text { de Entlebuch, Lapphund Finlandês, Golden Retriever, Karelian } \\
\text { Bear Dog, Kuvasz, Labrador Retriever, Lapponian Herder, Poodle } \\
\text { médio, Elkhound Norueguês, Retriever da Nova Escócia, Cão d'água } \\
\text { Português, Cão d'água Espanhol, Lapphund Sueco, Yorkshire Terrier }\end{array}$ \\
\hline
\end{tabular}

Nota: Adaptado de Downs et al. (2014).

Cooper et al. (2014) mostraram em seu estudo um tipo de APR desconhecido até então, em cães da raça Valhund Sueco. Os animais apresentavam sinais iniciais de degeneração com áreas de despigmentação variando de marrom a vermelho na região tapetal da retina, e sinais de afinamento da retina em animais com média de 4,3 anos de idade. No estágio final da doença, apresentavam um afinamento de quase toda a retina e sinais de cegueira noturna e déficit visual diurno ou até mesmo cegueira total em média após quatro anos.

Somma et al. (2017) descreveram um novo tipo de APR em cães da raça Whippet. 0 estudo demonstrou perda de função dos bastonetes e alterações no ERG antes da maturação da retina, antes de 1 mês de idade. Os cães jovens apresentavam nistagmo de maneira similar a dos seres humanos com ACL, característica que não foi encontrada em cães adultos com cegueira total. A fundoscopia de dois animais jovens revelou pequenas bolhas que se tornaram menos aparentes com a progressão da doença. 0 ERG demonstrou ausência de onda $b$ nos cães jovens e, com a progressão da perda de receptores, ausência total de ondas, culminando em cegueira total.

\section{Conclusão}

Os estudos a respeito das distrofias hereditárias da retina em cães são essenciais para proporcionar maior conhecimento quanto à patofisiologia e potenciais tratamentos em seres humanos. A oftalmologia comparativa proporciona a criação 
de modelos experimentais espontâneos para essas doenças a partir de avaliações dos animais doentes, pois o comportamento desse grupo de enfermidades é muito semelhante em seres humanos e animais. Muitas são as vantagens do estudo de modelos espontâneos de doenças frente à indução destas nesses animais, principalmente quanto ao aspecto ético. 0 conhecimento mais amplo a respeito das APRs possibilita a exploração dos complexos mecanismos genéticos e da correspondente patofisiologia envolvida. Este entendimento poderá proporcionar tratamentos inovadores como a terapia gênica, uma perspectiva alentadora de solução, tanto para humanos doentes quanto para animais doentes sob os cuidados de seres humanos, destas doenças que quase sempre levam à cegueira irreversível.

\section{Referências}

Acland GM, Aguirre GD. Retinal degenerations in the dog: IV. Early retinal degeneration (erd) in Norwegian elkhounds. Exp Eye Res. 1987;44(4):491-521.

Acland GM, Blanton SH, Hershfield B, Aguirre GD. XLPRA: a canine retinal degeneration inherited as an X-linked trait. Am J Med Genet. 1994;52(1):27-33.

Acland GM, Fletcher RT, Gentleman S, Chader GJ, Aguirre GD. Non-allelism of three genes ( $\mathrm{rcd} 1, \mathrm{rcd} 2$ and erd) for early-onset hereditary retinal deneration. Exp Eye Res. 1989;49(6):983-98.

Acland GM, Ray K, Mellersh CS, Gu W, Langston AA, Rine J, et al. Linkage analysis and comparative mapping of canine progressive rod-cone degeneration (prcd) establishes potential locus homology with retinitis pigmentosa (RP17) in humans. Proc Natl Acad Sci U S A. 1998;95(6):3048-53.

Aguirre G, Alligood J, O'Brien P, Buyukmihci N. Pathogenesis of progressive rod-cone degeneration in miniature poodles. Invest Ophthalmol Vis Sci. 1982;23(5):610-30.

Aguirre GD, Rubin LF. Progressive retinal atrophy (rod dysplasia in the Norwegian Elkhound. J Am Vet Med Assoc. 1971;158(2):208-18.
Aquirre G, Farber D, Lolley R, Fletcher RT, Chader GJ. Rod-cone dysplasia in Irish setters: a defect in cyclic GMP metabolism in visual cells. Science. 1978;201(4361):1133-4.

Bacellar M, Montiani-Ferreira F, Somma AT, BarrosFilho IR. História da eletrorretinografia. Arch Vet Sci. 2008;13(4):285-91.

Balicka A, Trbolová A, Vrbovská T. Electroretinography (A Review). Folia Vet. 2016;60(1):53-8.

Barnett KC, Curtis R. Lens luxation and progressive retinal atrophy in the Tibetan terrier. Vet Rec.1978;103(8):160.

Beltran WA. The use of canine models of inherited retinal degeneration to test novel therapeutic approaches. Vet Ophthalmol. 2009;12(3):192-204.

Bernardis I, Chiesi L, Tenedini E, Artuso L, Percesepe A, Artusi V, et al. Unravelling the complexity of Inherited Retinal Dystrophies Molecular Testing: added value of targeted next-generation sequencing. Biomed Res Int. 2016;2016:6341870.

Clements PJM, Gregory CY, Peterson-Jones SM, Sargan DR, Bhattacharya SS. Confirmation of the rod cGMP phosphodiesterase $\beta$ subunit (PDE $\beta$ ) nonsense mutation in affected rcd-1 Irish setters in the UK and development of a diagnostic test. Curr Eye Res. 1993;12(9):861-6.

Cooper AE, Ahonen S, Rowlan JS, Duncan A, Seppälä $\mathrm{EH}$, Vanhapelto $\mathrm{P}$, et al. A novel form of progressive retinal atrophy in Swedish vallhund dogs. PLoS One. 2014;9(9):e106610.

Curtis R, Barnett KC. Progressive retinal atrophy in miniature longhaired dachshund dogs. Brit Vet J. 1993;149(1):71-85.

Dantas AM. Eletrorretinografia. In: Dantas AM, Costa JGC, Neto Pacini L, Yamane R, Elias CA. Eletrofisiologia Ocular.1ed. Rio de Janeiro: Editora Cultura Médica; 1995. p. 141-225.

Djajadiningrat-Laanen SC, Boevé MH, Stades FC, van Oost BV. Familial non-rcd 1 generalized retinal degeneration in Irish setters. J Small Anim Pract. 2003;44(3):113-6. 
Downs LM, Hitti R, Pregnolato S, Mellersh CS. Genetic screening for PRA-associated mutations in multiple dog breeds shows that PRA is heterogeneous within and between breeds. Vet Ophthalmol. 2014;17(2):126-30.

Einthoven W, Jolly WA. The form and magnitude of the electrical response of the eye to stimulation by light at various intensities. Exp Physiol. 1908;1(4):373-416.

Ekesten B. Electrodiagnostic evaluation of vision. In: Gelatt KN, Gilger BC, Kern TJ (EE.). Veterinary Ophthalmology. 5 ed. New Jersey: Wiley-Blackwell; 2013. p. 684-702.

Gearhart PM, Gearhart CC, Petersen-Jones SM. A novel method for objective vision testing in canine models of inherited retinal disease. Invest Ophthalmol Vis Sci. 2008;49(8):3568-76.

Hamada S, Yoshida K, Chihara E. Optical coherence tomography images of retinitis pigmentosa. Ophthalmic Surg Lasers. 2000;31(3):253-6.

Hartong DT, Berson EL, Dryja TP. Retinitis pigmentosa. Lancet. 2006;368(9549):1795-809.

Hohman TC. Hereditary Retinal Dystrophy. Handb Exp Pharmacol. 2017;242:337-67.

Huang Y, Cideciyan AV, Papastergiou GI, Banin E, Semple-Rowland SL, Milam AH, et al. Relation of optical coherence tomography to microanatomy in normal and rd chickens. Invest Ophthalmol Vis Sci. 1998;39(12): 2405-16.

Huang D, Swanson EA, Lin CP, Schuman JS, Stinson WG, Chang W, et al. Optical coherence tomography. Science. 1991;254(5035):1178-81.

Kennedy CJ, Rakoczy PE, Constable IJ. Lipofuscin of the retinal pigment epithelium: a review. Eye (Lond). 1995;9(Pt 6):763-71.

Kijas JW, Miller BJ, Pearce-Kelling SE, Aguirre GD, Acland GM. Canine models of ocular disease: outcross breedings define a dominant disorder present in the English mastiff and bull mastiff dog breeds. J Hered. 2003;94(1):27-30.
Komáromy AM, Abrams KL, Heckenlively JR, Lundy SK, Maggs DJ, Leeth CM, et al. Sudden acquired retinal degeneration syndrome (SARDS) - a review and proposed strategies toward a better understanding of pathogenesis, early diagnosis, and therapy. Vet Ophthalmol. 2016;19(4):319-31.

Komáromy AM, Smith PJ, Brooks DE. Electroretinography in dogs and cats. Part I. Retinal morphology and physiology. Compend Contin Educ Vet. 1998;20(3):343-51.

Kropatsch R, Akkad DA, Frank M, Rosenhagen C, Altmüller J, Nürnberg P, et al. A large deletion in RPGR causes XLPRA in Weimaraner dogs. Canine genetics and epidemiology. 2016;3:7.

Le Meur G, Stieger K, Smith AJ, Weber M, Deschamps JY, Nivard D, et al. Restoration of vision in RPE65deficient Briard dogs using an AAV serotype 4 vector that specifically targets the retinal pigmented epithelium. Gene Ther. 2007;14(4):292-303.

Mellersh CS, Boursnell ME, Pettitt L, Ryder EJ, Holmes NG, GrafhaM D, et al. Canine RPGRIP1 mutation establishes cone - rod dystrophy in miniature longhaired dachshunds as a homologue of human Leber congenital amaurosis. Genomics. 2006;88(3):293-301.

Miyadera K, Acland GM, Aguirre GD. Genetic and phenotypic variations of inherited retinal diseases in dogs: the power of within-and across-breed studies. Mamm Genome. 2012;23(1-2):40-61.

Naldini L. Gene therapy returns to center stage. Nature. 2015;526(7573):351-60.

Ofri R. Optics and Physiology of Vision.. In: Gelatt KN, Gilger BC, Kern TJ (EE.). Veterinary Ophthalmology. 5 ed. New Jersey: Wiley-Blackwell; 2013. p. 208-70.

Parshall CJ, Wyman M, Nitroy S, Acland GM, Aguirre GD. Photoreceptor dysplasia: an inherited progressive retinal atrophy of miniature schnauzer dogs. Prog Vet Comp Ophthalm. 1991;1(3):187-203.

Petersen-Jones SM. A review of research to elucidate the causes of the generalized progressive retinal atrophies. Vet J. 1998b;155(1):5-18. 
Petersen-Jones SM. Advances in the molecular understanding of canine retinal diseases. J Small Anim Pract. 2005;46(8):371-80.

Petersen-Jones SM. Animal models of human retinal dystrophies. Eye (Lond). 1998a;12(Pt 3b):566-70.

Petersen-Jones SM, Entz DD, Sargan DR. cGMP phosphodiesterase- $\alpha$ mutation causes progressive retinal atrophy in the Cardigan Welsh corgi dog. Invest Ophthalmol Vis Sci. 1999l;40(8):1637-44.

Petersen-Jones SM. Current DNA-based tests for hereditary eye disease. Vet Ophthalmol. 2001;4(4): 233-6.

Somma AT, Moreno JCD, Sato MT, Rodrigues BD, BacellarGaldino, M, Occelli LM, et al. Characterization of a novel form of progressive retinal atrophy in Whippet dogs: a clinical, electroretinographic, and breeding study. Vet Ophthalmol. 2017;20(5):450-9.
Suber ML, Pittler SJ, QIN N, Wright GC, Holcombe V, Lee $\mathrm{RH}$, et al. Irish setter dogs affected with rod/cone dysplasia contain a nonsense mutation in the rod cGMP phosphodiesterase beta-subunit gene. Proc Natl Acad Sci USA. 1993;90(9):3968-72.

Svensson M, Olsén L, Winkler PA, Petersen-Jones SM, Bergström T, Garncarz Y, et al. Progressive retinal atrophy in the Polski Owczarek Nizinny dog: a clinical and genetic study. Vet Ophthalmol. 2016;19(3):195-205.

Switonski M. Dog as a model in studies on human hereditary diseases and their gene therapy. Reprod Biol. 2014;14(1):44-50.

Vilboux T, Chaudieu G, Jeannin P, Delattre D, Hedan B, Bourgain $C$, et al. Progressive retinal atrophy in the Border Collie: A new XLPRA. BMC Vet Res. 2008;4:10.

Wolf ED, Vainisi SJ, Santos-Anderson R. Rod-cone dysplasia in the collie. J Am Vet Med Assoc. 1978;173(10):1331-3. 